\title{
Questão Social e favela: violência estatal, pandemia e organização da classe trabalhadora
}

\author{
The Social issue and the favela: State violence, pandemic, and working-class \\ organization
}

\section{Francine Helfreich Coutinho dos SANTOS ${ }^{*}$}

https://orcid.org/oooo-00o1-9411-5818

Eblin FARAGE ${ }^{* *}$

https://orcid.org/oooo-0002-6307-8062

\author{
Marina Barbosa PINTO* \\ https://orcid.org/oooo-0002-7619-0571
}

\begin{abstract}
Resumo: A proposta do seguinte texto consiste em discutir o cotidiano das favelas, marcadas pela violência estatal; cotidiano que no contexto da pandemia da Covid-19 reitera seu caráter de classe. Locais onde esse expressa a ação precarizada do Estado - no que se refere às demandas sociais - ao mesmo tempo em que o mesmo efetiva a presença de seu braço armado sob a retórica de manutenção da ordem e de controle da violência. O texto apresenta a construção histórica das favelas no Rio de Janeiro; o debate do cotidiano, atravessado pela presença política do Estado para a "in"segurança; e alguns elementos sobre as formas de resistência construídas pelos segmentos da classe trabalhadora que vivem nas favelas. A metodologia utilizada se expressa em três eixos: a realização de uma pesquisa exploratória para atingir os objetivos propostos inicialmente; a revisão bibliográfica dialogando com autores clássicos e contemporâneos; e a pesquisa qualitativa.
\end{abstract}

Palavras-chave: Favela. Pandemia. Organização dos trabalhadores.

Abstract: This text discusses daily life in the favelas, which is marked by State violence that, in the context of the Covid-19 pandemic, reiterates its class character. These are places where the destabilizing actions of the State are expressed - regarding social demands - while simultaneously imposing the presence of its armed forces under the rhetoric of maintaining order and controlling violence. The text

\footnotetext{
* Assistente Social. Doutora em Serviço Social. Professora da Escola de Serviço Social da Universidade Federal Fluminense (UFF), e do Programa de Pós-Graduação em Serviço Social e Desenvolvimento Regional da UFF. (UFF, Niterói, Brasil). R. Alexandre Moura, 8, São Domingos, Niterói (RJ), CEP.: 24210-200. E-mail: farage.eblin@gmail.com.

** Assistente Social. Doutora em Serviço Social. Professora da Escola de Serviço Social da Universidade Federal Fluminense (UFF), do Programa de Pós-Graduação em Serviço Social e Desenvolvimento Regional da UFF. (UFF, Niterói, Brasil). R. Alexandre Moura, 8, São Domingos, Niterói (RJ), CEP.: 24210-200. E-mail: francinesantos@yahoo.com.br.

Assistente Social. Doutora em História. Professora associada da Faculdade de Serviço Social da Universidade Federal de Juiz de Fora. (UFJF, Juiz de Fora, Brasil). Rua José Lourenço Kelmer, s/n,Campus Universitário Bairro São Pedro, Juiz de Fora (MG), CEP: 36036-90o. E-mail: marinabp29@gmail.com.
} Atribuição 4.0 Internacional (https://creativecommons.org/licenses/by/4.o/deed.pt_BR), que permite copiar e redistribuir o material em qualquer suporte ou formato, bem como adaptar, transformar e criar a partir deste material para qualquer fim, mesmo que comercial. O licenciante não pode revogar estes direitos desde que você respeite os termos da licença. 
presents the historic construction of the favelas in Rio de Janeiro; the everyday discussions, colored by the political presence of the State for "in"security; and some elements around the forms of resistance built by the working class sectors that live in the favelas. The methodology used is expressed along three axes: exploratory research to reach the proposed objectives, bibliographic review dialoguing with classic and contemporary authors, and qualitative research.

Keywords: Favela. Pandemic. Workers' organization.

Submetido em: 1/7/2020. Revisado em: 26/9/2020; 12/10/2020. Aceito em: 13/10/2020.

\section{Introdução}

$\mathrm{U}$ m dos maiores poetas brasileiros, Carlos Drummond de Andrade, há 41 anos, nos presenteava com uma poesia que tratava das favelas, indagando: "São 200, são 300 as favelas cariocas? O tempo gasto em contá-las é tempo de outras surgirem. 8oo mil favelados ou já passa de 1 milhão?[...]” (ANDRADE, 1979). Com toda sua potência e sensibilidade histórico-política, o poeta retratava o cotidiano das favelas nas suas dores e dissabores. Após quatro décadas, as perguntas parecem oportunas, já que, segundo o Censo IBGE de 2010, mais de 1,3 milhão de pessoas viviam nas favelas do Rio de Janeiro. De certo, os moradores das favelas e periferias brasileiras se ampliam diante da crise do capitalismo e da recessão gerada na busca desenfreada pelo lucro. As múltiplas questões que atravessam o cotidiano das favelas nos instigam a pensar sobretudo neste período tão singular da pandemia do novo coronavírus - sobre as alternativas criadas pelos trabalhadores diante das diferentes formas de violência produzidas pelo Estado.

A reflexão sobre o cotidiano dos moradores da favela se apresenta como uma das condições necessárias para uma correta análise das formas de viver e resistir na sociedade burguesa contemporânea, as quais estão atravessadas pelo recrudescimento das contradições e imposições do capital; assim como também pelas lutas forjadas coletiva e individualmente no interior dos segmentos da classe trabalhadora. Analisar o real, o cotidiano - referenciado em conhecimento crítico historicamente produzido - é necessariamente estimular a reflexão sobre as relações sociais e os embates entre as classes sociais. É dar, em um mesmo movimento, visibilidade ao cotidiano de segmentos pauperizados da classe trabalhadora e de seu enfrentamento com as políticas de um Estado propagador de intervenções e gestões exponencialmente genocidas, cujo alvo privilegiado é o conjunto de sujeitos concretos presentes nos territórios e espaços populares. Tais determinantes impactam a singularidade dos moradores de favela e tornam necessários estudos que identifiquem as estratégias e formas autônomas de organização e de sobrevivência que esses sujeitos constroem no momento de agravamento da crise estrutural do capital; evidenciado, entre outros, na pandemia da COVID-19.

Segundo Arroyo (2001, p. 12),

Quando partimos do viver concreto, historicamente contextualizado e determinado dos coletivos populares, somos levados a aprofundar mais no padrão de dominação em que foram segregados e alocados os diversos coletivos populares. Não apenas um povo genérico, mas cada coletivo com sua segregação: indígenas, negros, mestiços, caboclos, comunidades periféricas, das cidades e dos campos. Que lugar-não-lugar lhes foi reservado nos padrões

Argum., Vitória, v. 12, n. 3, p. 117-131, set./dez. 2020. | ISSN 2176-9575 
de poder, de trabalho, de apropriação-expropriação da terra, do espaço urbano, dos territórios, da justiça, do conhecimento, da saúde, do reparto da riqueza coletiva (ARROYO, 2001, p. 12).

Há o consenso de que a pandemia atinge indiscriminadamente pessoas de todas as nacionalidades, gêneros, cores e classes sociais. Contudo, atinge de forma mais aguda aqueles que vivem nas favelas e periferias, em virtude da absoluta desestruturação das políticas públicas e sociais, acrescida da intensificação da violência policial e dos grupos criminosos armados. A profunda desigualdade social e econômica que gera ausência de alimentação adequada, precariedade dos domicílios e acesso deficitário ao saneamento básico, articulada à impossibilidade de isolamento face às demandas laborativas, são elementos que reiteram a suscetibilidade dessa população à contaminação e morte pela Covid-19.

Dentro dessa realidade, as contradições constitutivas do sistema capitalista se agudizam; pois, nos momentos de crise ${ }^{1}$, há reorganização das relações, tendo como eixo a intensificação das medidas relacionadas à mundialização do capital $^{2}$ e à recuperação das taxas de lucro. Para tal, o sistema capitalista exige uma reconfiguração das relações produtivas, a partir dos pressupostos neoliberais nas relações de trabalho ${ }^{3}$, da reestruturação das políticas sociais a partir da privatização e, por conseguinte, da desconfiguração das mesmas como mediação de direitos sociais ${ }^{4}$. Tais modificações se traduzem para a classe trabalhadora em instrumentos de precarização de vida, naturalização da miséria e da morte, e como recrudescimento das expressões da Questão Social. Aqui trabalharemos com a perspectiva de que essas são as expressões do processo de formação e desenvolvimento da classe operária e de seu ingresso no cenário político da sociedade, exigindo assim o seu reconhecimento como classe por parte do empresariado e do Estado. "É a manifestação, no cotidiano da vida social, da contradição entre o proletariado e a burguesia, a qual passa a exigir outros tipos de intervenção, mais além da caridade e repressão" (IAMAMOTO; CARVALHO, 1995, p. 128-129).

A atual análise parte de experiências profissionais de inserção na favela da Maré, por mais de dez anos, no papel de assistentes sociais e pesquisadoras; assim como das experiências extencionistas em favelas a partir da prática docente das autoras. A experiência profissional, que em parte substancia as análises do artigo, entre pesquisas diversas, também resultou em dissertações e teses. Todo o estudo e produção acadêmica derivados das experiências - articuladas a estudos bibliográficos e a outras pesquisas -, dialoga com questões consideradas prementes para aqueles que são confrontados radicalmente com os antagonismos desta sociedade e que se colocam na defesa da vida digna e da liberdade. Logo, tais questões apresentam-se como indispensáveis ao Serviço Social, no âmbito da formação e do fazer profissional dos

\footnotetext{
${ }_{1}^{1}$ Compartilhamos das reflexões que afirmam as crises como fases de recessão e depressão do capitalismo, correspondentes à lógica do sistema e não a elementos casuais e/ou acidentais. Apoiamonos em estudos de Mandel (1990).

2 Para maior compreensão do tema, ver Chesnais (1996).

3 Este tema está detalhado em Antunes (1999).

4 Uma boa análise sobre o tema está em Behring; Boschetti (2006).
} 
assistentes sociais, à medida que as construções profissionais solicitam a necessária interação com os trabalhadores e segmentos de classe residentes nas periferias.

Assim, o presente artigo se divide em três partes - além dessa breve introdução. A primeira parte aborda aspectos da favela, como concepção, processualidade histórica e as particularidades da cidade do Rio de Janeiro. A segunda trata dos aspectos relacionados ao cotidiano da favela no que tange à intervenção do Estado, à política de (in)segurança pública e à organização dos trabalhadores e trabalhadoras; e por último, a terceira parte apresenta uma guisa de conclusões reflexivas.

\section{Favelas e questão social no Rio de Janeiro}

Partimos do pressuposto de que a favela ${ }^{5}$, enquanto parte da cidade, reúne as condições gerais para a produção e os meios de reprodução do capital e do trabalho, de modo que ficam explícitas as contradições das relações construídas a partir da apropriação privada da riqueza socialmente produzida. Assim, as reflexões partem da premissa de que as manifestações da Questão Social possuem configurações diferenciadas, que se modificam segundo as características específicas de cada país, de cada região; bem como do seu nível de inserção e aprofundamento nos marcos da mundialização do capital.

Considerando que a Questão Social é indissociável do processo de acumulação e dos efeitos que produz sobre o conjunto da classe trabalhadora, a pauperização da população constituiu o aspecto imediato da instauração do capitalismo em sua fase industrial-concorrencial. Como afirma Netto, pela primeira vez, "[...] a pobreza crescia na proporção que aumentava a capacidade de produzir riquezas!" (NETTO, 2001, p. 42). Se nas formas de sociedade anteriores à sociedade burguesa a pobreza estava ligada a um quadro geral de escassez, agora, na sociedade industrial neoliberal, ela se mostra conectada a um quadro geral tendente a reduzir a escassez, mas sem reduzir a pobreza.

$\mathrm{Na}$ medida em que manifestações da classe trabalhadora se potencializam como ameaça de ruptura da ordem - pondo em risco a prosperidade dos negócios capitalistas e a estabilidade das instituições políticas e sociais - estabelece-se o conflito entre classes sociais; conflito esse que deflagra a emergência de respostas do capitalismo, tendo em vista sua manutenção como modo de produção que determina as relações sociais de exploração. Assim, a lei geral da acumulação capitalista (Marx, 2003) revela a anatomia da Questão Social, sua complexidade e seu caráter necessário para o desenvolvimento capitalista em todas as suas fases. Portanto, as favelas estão

\footnotetext{
5 Dialogamos aqui com uma concepção de favela que considera: a) insuficiência histórica de investimentos do Estado e do mercado formal, principalmente imobiliário, financeiro e de serviços; b) Forte estigmatização socioespacial, especialmente inferida por moradores de outras áreas da cidade; c) apropriação social do território com uso predominante para fins de moradia; d) ocupação marcada pela alta densidade de habitações; e) indicadores educacionais, econômicos e ambientais abaixo da média do conjunto da cidade; f) níveis elevados de subemprego e informalidade nas relações de trabalho; g) taxa de densidade demográfica acima da média do conjunto da cidade; h) ocupação de sítios urbanos marcados por um alto grau de vulnerabilidade ambiental; i) alta concentração de negros (pardos e pretos); j) grau de soberania por parte do Estado inferior à média do conjunto da cidade; k) alta incidência de situações de violência, sobretudo a letal, acima da média da cidade; l) relações de vizinhança marcadas por intensa sociabilidade (SILVA, 2009. p. 22-23).
} 
diretamente relacionadas à lógica de reprodução capitalista que gera espaços e territórios desiguais, produzindo espaços populares, periferias e favelas; e em contraponto, gerando espaços onde vivem pessoas com maior poder de compra. É o capitalismo que se desenvolve de forma desigual e combinada, gerando também desigualdades espaciais.

O processo de urbanização brasileiro tem seu marco nas transformações erigidas a partir de 1930. Tal projeto, ancorado no binômio industrialização-urbanização, demandou a ampliação do intervencionismo econômico com o objetivo de construir as bases necessárias para a modernização, conjugadas à criação de significativo aparato público de política social. Entre os objetivos estava a regulação das expressões da Questão Social em um contexto marcado pela dinâmica desigual e combinada de um processo de urbanização que incorporaria as particularidades de uma economia capitalista periférica e dependente. O surgimento das favelas no Brasil, mais especificamente no Rio de Janeiro, acompanha esse desenvolvimento urbanoindustrial.

Conforme Fernandes (1991), o Brasil traz a marca de um desenvolvimento desigual e combinado; onde elementos do arcaico e do moderno, ao dialogarem, produzem um padrão dual de expropriação. De um lado temos a expansão monopolista no Brasil articulada com a dominação imperialista; de outro, a burguesia operando o Estado como instrumento de unificação da classe burguesa - e, através dele, impondo seus interesses, valores e ideologias ao conjunto da sociedade; tendo assim papel decisivo na modernização pelo alto (FERNANDES, 1991) ${ }^{6}$. Opera-se, portanto, uma dicotomia entre Estado e classe trabalhadora, ficando essa alijada dos processos de transformação política; fato que se reproduz em maior escala nos espaços populares.

Com a expansão da industrialização/urbanização, as favelas se constituíram como um 'problema urbanístico e social' que desafia a administração pública desde o início do século XX. Nessa conjuntura, onde alterações políticas e econômicas impulsionaram processos migratórios do campo para a cidade, as favelas foram incluídas nos planos de intervenção pública. As intervenções do Estado frente às manifestações da Questão Social nas favelas vieram por força da necessidade de garantir a reprodução da força de trabalho; ou por reivindicações da própria população. A construção sem planejamento urbano, a autoconstrução por força da necessidade de moradia sem incentivo do Estado e a avidez do capital - que gradativamente 'descobriu' a favela como lugar lucrativo contribuíram para que a cidade do Rio de Janeiro se tornasse exemplo da reorganização geográfica à qual, segundo Harvey (2006), o capitalismo recorre para resolver seus impasses e crises. Nessa lógica, o capitalismo constrói uma geografia marcada pela desigualdade, o que facilita a acumulação do capital e produz territórios proletarizados destituídos de bens e serviços de qualidade.

O Rio de Janeiro expressa uma mescla na forma como as classes conformam o espaço urbano. A aproximação territorial entre os sujeitos que compõem as distintas classes marca a lógica de organização do território. A concentração de favelas em bairros nobres da cidade evidencia esta aproximação, mas também há que se considerar a

${ }^{6}$ Para mais informações ver Fernandes (1991). 
diversificação dos espaços e a aproximação com bairros da periferia. Inúmeras iniciativas de oferta de políticas e serviços públicos desconsideraram as especificidades destes espaços, as homogeneizaram e as mantiveram em um lugar subalterno em comparação a outros territórios da cidade. Esses elementos nos ajudam a pensar como a intensa segregação socioespacial e o modo desigual como o Estado se faz presente em cada território agrava e complexifica as expressões da Questão Social, em seus traços de desigualdade e resistência.

\section{Violência estatal, insegurança e a pandemia da Covid-19}

No presente tópico abordaremos a realidade das favelas no momento da pandemia da COVID-19 no Rio de Janeiro, considerando sua construção histórica como expressão da Questão Social e sua diversidade; a forma como o Estado, através dos entes federativos, trata a população desses territórios; e também algumas de suas formas autônomas de organização.

Diante da histórica desigualdade produzida pela conformação desigual do espaço urbano, nos termos de Harvey (2006), como fruto do desenvolvimento desigual e combinado do capitalismo, as populações das favelas e periferias urbanas buscam formas de sobreviver diante das diversas ações de extermínio impulsionadas pelo Estado. Os diferentes governos, em âmbito federal, estadual e municipal, programam, nas periferias, uma necropolítica7: seja através da ação violenta das polícias; pela total ineficiência das políticas públicas de combate à pandemia da COVID-19; ou pela subjugação aos interesses do capital de garantir os lucros ante a preservação das vidas.

\subsection{A política do Estado para a insegurança nas favelas}

O Estado, compreendido nesta análise como um aparelho privado da hegemonia da burguesia, pressupõe considerar as disputas como inerentes à busca pela hegemonia por determinada classe social. Nesse sentido, considera-se a hegemonia como base para a manutenção dos interesses da classe hegemônica economicamente e do desenvolvimento capitalista, tendo o Estado como estrutura fundamental, como afirma Gramsci (2000). Assim, o Estado cumpre função essencial na organização espacial e territorial da cidade, diferenciando espaços no que tange à distribuição e qualidade dos equipamentos públicos, à organização espacial, à garantia de direitos sociais, às políticas públicas e também à forma como a segurança pública atua.

De forma hegemônica, o Estado, através dos governos estadual e municipal, impõe uma rotina diferenciada aos territórios periféricos, fazendo com que esses espaços que poderiam ser de diálogo, construção coletiva e interação - sejam de disputa violenta pelo domínio de grupos criminosos armados, quer sejam esses oficialmente ligados ao Estado (como a polícia), ou demais grupos, como milícia e facções de

\footnotetext{
7 Necropolítica é um conceito criado pelo professor camaronense Achille Mbembe, que se refere às escolhas políticas que o Estado faz ao desenvolver sua política de segurança, e as demais políticas públicas direcionadas para as populações mais pobres. Nessa perspectiva, segundo o autor, há uma 'escolha' implícita entre quem deve viver e morrer através da negação da humanidade de alguns segmentos da população, especificamente os negros e negras, maioria dos moradores dos territórios periféricos.
} 
drogas. Em ambos os casos, há anuência do Estado na forma como esses grupos se organizam e atuam nas favelas; seja através da orientação explícita - como na fala do governador do Rio de Janeiro, Wilson Witzel, ao defender que "O correto é matar o bandido que está de fuzil. A polícia vai fazer o correto: vai mirar na cabecinha e... fogo! Para não ter erro" (WILSON..., 2018, não paginado) -, seja no pacto lucrativo de manutenção dos grupos ligados ao narcotráfico para o domínio desses territórios ${ }^{8}$.

O 'olhar' do poder público, expresso em suas políticas públicas e ações, revela a orientação política para a forma como o Estado compreende os espaços das favelas e a perspectiva estereotipada, homogeneizadora e criminalizante com que são identificados seus moradores. Desse modo, as políticas públicas e sociais se revelam uma ação pobre para os pobres: sempre de baixa qualidade, seletivas, excludentes e reforçadoras do 'lugar' socialmente atribuído aos segmentos da classe trabalhadora - o da subalternização. De forma geral, a maior parte das políticas públicas reforçam os estigmas e a subalternização dos moradores das periferias, nunca apontando uma perspectiva emancipatória, como explicitam Farage (2012) e Silva ES (2009) em suas teses.

Assim, as escolas públicas, apesar de presentes nas favelas, em sua maioria, são de baixa qualidade - sem educação em tempo integral, com parcos recursos e possibilidades, cumprindo mais a formalidade do que o projeto de uma educação que ensine a ler o mundo. $\mathrm{O}$ mesmo ocorre com postos de saúde, vilas olímpicas, equipamentos culturais e Centros de Referência da Assistência Social (CRAS); ou seja, parcos recursos para grandes demandas. Portanto, é importante rebater o discurso de que o Estado está ausente das favelas - muito presente na literatura da área e na forma como a grande mídia e parte dos intelectuais compreendem a ação do Estado nesses territórios. Afirmamos o contrário, o Estado está presente, porém com uma ação direcionada para uma inclusão excludente através do acesso a serviços e direitos de baixa qualidade. Essa tese é aprofundada é defendida por Silva ES (2009), Farage (2012) e SILVA JS (2009), a partir de um conjunto de estudos sobre a favela da Maré e outros territórios da cidade do Rio de Janeiro. A favela da Maré é uma boa expressão da relação do Estado com os territórios favelados. Hoje possui 29 escolas públicas, 10 postos de saúde, uma lona cultural, uma vila olímpica, uma batalhão da polícia militar; e ainda assim oferta os serviços de baixa qualidade na companhia de uma violência cotidiana expressa nos conflitos armados, que entre outras coisas incide em alteração do horário escolar no território. Além dos fechamentos constantes dos equipamentos públicos e da ausência de profissionais para suprir a demanda desses equipamentos.

A tese do Estado presente, com ações direcionadas, explicita-se na política de insegurança gestada pelo poder público através de ações violentas, ostensivo uso de armas e inúmeras violações de direitos. Os números falam por si. No Rio de Janeiro, um dos poucos estados onde se instituiu o "auto de resistência" ${ }^{\text {, }}$, esse funciona como

\footnotetext{
8 Para ver mais sobre essa relação entre Estado e grupos criminosos armados, Farage (2012), Fernandes (2011) e Silva ES (2009).

${ }^{9}$ Auto de resistência é quando há o assassinato de alguém pela polícia e esta informa que o "suspeito" reagiu e o disparo da polícia foi em legítima defesa. Assim, a maior parte desses assassinatos não são investigados. Segundo o Instituto de Segurança Pública do Rio de Janeiro, só entre 2013 e 2014, foram
} 
um verdadeiro direito para matar pobres e negros, sendo a polícia responsável por centenas de assassinatos. Segundo dados do Centro de Estudos e de Segurança e Cidadania (CESEC), em 2020 ocorreram 741 mortes causadas por policiais nos 5 primeiros meses do ano. São quase 5 pessoas mortas por dia pela polícia no Rio de Janeiro. Sendo que o levantamento do Instituto de Segurança Pública do Rio de Janeiro (ISP-RJ) mostra que $78 \%$ das pessoas mortas pela intervenção policial em 2019 são pretas ou pardas.

A política de segurança pública insuficiente e inadequada também prejudica crianças e adolescentes quanto ao direito à educação. Em 2016, dos 200 dias do ano letivo, em 157 houve escolas e creches cariocas fechadas. Estudo da Agência Brasil mostra que das 1.537 escolas e creches municipais no Rio, 381 ficaram fechadas um ou mais dias durante o primeiro semestre de 2017 por causa de tiroteios ou similares. Nas escolas municipais, 129.165 alunos ficaram sem aulas por períodos que variaram entre 1 e 15 dias, o equivalente a $20,12 \%$ do total da rede municipal (641.655 alunos). Só no primeiro semestre de 2017, em 99 dias dos 107 dias de ano letivo, escolas e creches tiveram de fechar as portas. Das 388 escolas e creches municipais que tiveram aulas paralisadas por causa de tiroteios, 36 escolas e creches não funcionaram nove dias ou mais no período.

Sob tal cotidiano de violações de direitos, os segmentos da classe trabalhadora residentes nas favelas vivem a intensificação da precariedade de suas condições de existência no período da pandemia da COVID-19, como destacado a seguir.

\subsection{Dimensões do cotidiano das favelas em tempos de pandemia}

As favelas, historicamente marcadas pela desigualdade e pela ação direcionada do Estado de forma homogeneizante, estigmatizada, criminalizante e violenta, neste período de pandemia sofrem de forma ainda mais intensa. O cotidiano compreendido como "[...] o espaço heterogêneo no qual se inter-relacionam dinamicamente os dois polos humanos da realidade social: a particularidade e a genericidade [...]" (IASI, 2006, p. 26) - se torna o espaço das manifestações das múltiplas determinações de um Estado de classe que expressa a crise do capitalismo.

Nos marcos do desenvolvimento desigual e combinado do capitalismo, que articula formas distintas de exploração com dimensões ideológicas essenciais à manutenção do status quo e à submissão dos pauperizados à ordem social, há uma estrutura social urbana profundamente segregadora. Visibilizar as dimensões do cotidiano das classes populares possibilita a aproximação das experiências de vivência às estratégias de sobrevivência e às formas do viver construídas pelos moradores da favela. Por outro lado, esse mesmo exercício possibilita identificar as contradições presentes na constituição dos territórios populares e na vida dos sujeitos, evidenciando assim ações e reações aos poderes instituídos, visibilizando a ação do Estado, dos equipamentos privados de hegemonia, dos sujeitos coletivos e das organizações que compõem o espaço da favela.

assassinadas 481 pessoas sob a alegação do auto de resistência. O auto de resistência não é regulado por nenhuma lei, mas tem respaldo no artigo 292 do Código de Processo Penal. 
Compreende-se, como Lefebvre (1991), que o cotidiano é o espaço da contradição e da resistência, ao mesmo tempo que expressa as determinações mais gerais da lógica capitalista; sem contudo ser apenas um espaço de reificação. Para Lefebvre (1991), o cotidiano

Seria algo mais: não uma queda vertiginosa, nem um bloqueio ou obstáculo, mas um campo e uma renovação simultânea, uma etapa e um trampolim, um momento composto de momentos (necessidades, trabalho, diversão produtos e obras - passividade e criatividade - meios e finalidades etc.), interação dialética da qual seria impossível não partir para realizar o possível (a totalidade dos possíveis) (LEFEBVRE, 1991, p. 20).

Para o autor, o cotidiano se constitui como a primeira esfera dos sentidos, representando a possibilidade de salto e de projeção, espaço de assimilações, de criação e recriação, de representações e subjetividades que constroem e dão sentido à vida real. Dessa forma o cotidiano é permeado pelo processo de representação dos sujeitos que, a partir de sua vivência e da maneira como elaboram suas experiências e vivências determinadas pelas relações sociais, acabam por constituir uma dada consciência social.

Nessa análise a valorização do cotidiano é fundamental para a compreensão das representações construídas e atribuídas a determinados segmentos sociais. Seguimentos esses que projetam sua própria existência não apenas pela sua realidade objetiva e material, mas também pela representação socialmente construída sobre sua existência, conciliando dimensão objetiva e subjetiva dos sujeitos. Assim, todas as tentativas de tirar da invisibilidade as condições de vida dos moradores das periferias brasileiras, em especial no momento de pandemia, se tornam centrais para o projeto de combate à segregação social e racial que estrutura o capitalismo e a política brasileira.

O cotidiano se acirra degradando as condições de vida dos segmentos da classe trabalhadora residentes nesses territórios. A precariedade, estruturante das políticas públicas ofertadas pelo Estado, neste momento, se expressa de forma mais contundente como negação absoluta de direitos. A população favelada compõe, em sua maioria, os mais de 8 o milhões de brasileiros que, segundo o Instituto Brasileiro de Geografia e Estatística (IBGE), estão sem nenhum tipo de trabalho ou fazem parte dos cerca de 30 milhões de brasileiros inseridos em trabalho informal no mês de maio de 2020.

Os dados da informalidade e do desemprego revelam a realidade de vida de uma grande parte da população residente nas favelas. A essa realidade se agrega a precarização dos serviços públicos - com postos de saúde mal equipados e com poucos profissionais qualificados; escolas públicas sem professores; ausência ou precariedade de equipamentos de cultura; assistência social desestruturada e sem programas que atendam a população em situação de pobreza; além da ação policial violenta. Toda essa precariedade tem se explicitado no número cada vez maior de moradores infectados; 
de profissionais da área da assistência social contaminados ${ }^{10}$ ao atuar na linha de frente dos CRAS; de agentes comunitários de saúde contaminados; da subnotificação de casos dos moradores de favelas pela desestruturação das Unidades de Pronto Atendimento (UPA), e pela ausência de testagem em larga escala. Mais uma vez, os moradores das favelas e os profissionais que aí trabalham são invisibilizados pelo Estado.

Outra dimensão relevante do cotidiano ${ }^{11}$ das favelas são as limitações reais para o processo de isolamento social. Além das residências, em sua maioria, serem muito pequenas e abrigarem número considerável de pessoas para suas dimensões, não contam com coleta de resíduos sólidos e há ausência ou precariedade das condições de saneamento; de modo que milhares de domicílios não têm acesso sequer à água. Uma parte de seus moradores, na busca pela sobrevivência, são subempregados, autônomos ou trabalhadores ambulantes, não tendo assim direito ao isolamento social. Esses trabalhadores, todos os dias, enfrentam ônibus lotado, atendem ao público em supermercados e padarias ou como entregadores, motoristas, trabalhadores da limpeza e porteiros, entre outras ocupações consideradas essenciais. E assim, a eles não é dado o direito do isolamento social e nem mesmo as garantias mínimas para a sua prevenção - como EPI adequados, transporte vazio, revezamento no trabalho para menor exposição, água nas torneiras de suas casas para higienização, atendimento adequado nas UPA e segurança ${ }^{12}$ para sair e chegar às suas residências. Como exigir isolamento social dos trabalhadores que precisam lutar pela vida cotidianamente? Como evitar a contaminação nas periferias brasileiras?

\subsection{A reação dos trabalhadores - a auto-organização}

Refletir sobre os processos organizativos e auto-organizativos de segmentos da classe trabalhadora na atualidade exige reconhecê-los como forjados por sujeitos sociais, que ao mesmo tempo são produto e produzem a realidade na qual se manifestam. Para decifrá-los em sua integralidade há que identificar as determinações estruturais e a dinâmica conjuntural.

O sistema capitalista tem nas três últimas décadas, em resposta à sua crise, intensificado a ofensiva sobre o trabalho e os processos de reprodução social. Tal cenário condensa as reações de diferentes segmentos sociais em diferentes formas organizativas - desde os setores mais clássicos da classe trabalhadora em suas formas também clássicas (sindicatos e partidos), como também diferentes experiências que inovam nas formas organizativas e de luta, e agregam trabalhadores, desempregados, juventude, negros e negras, mulheres e setores mais precarizados. Setores esses que concorrem na luta pela saúde, educação, transporte, moradia, lazer, democracia, emprego, em síntese: pelo direito à vida plena na cidade. Prevalece a luta para manter

\footnotetext{
${ }^{10}$ A ausência de equipamentos de proteção individual (EPI) e até mesmo a ausência de hábito no uso, tem levado um número cada vez maior de assistentes sociais a se contaminarem no trabalho nas favelas, com a população em situação de rua, nos hospitais, UPA, CRAS, postos de saúde, entre outros. ${ }^{11}$ Para saber mais sobre cotidiano das Favelas ver Farage (2012), Silva JS (2009), Silva (2007) e Valladares (2005).

${ }^{12}$ Só após quase três meses de isolamento social foi possível, no caso do Rio de Janeiro, garantir a suspensão das incursões policiais nas favelas, a partir da ação do Supremo Tribunal Federal ao julgar a ADPF 635, no dia 05 de junho de 2020.
} 
conquistas básicas neste momento de pandemia. E o mais básico de todos é estar vivo. Só então, se luta para tentar não perder direitos consolidados, pois o avanço ideológico, político e militar das forças capitalistas em todo o planeta vem se consolidando.

Diante de tal contexto, à classe trabalhadora é reservado um recrudescimento da exploração por meio de novas configurações nas relações de compra e venda da sua força de trabalho, bem como uma destruição permanente do arcabouço jurídico e social de reconhecimento e efetivação de direitos concernentes à sua reprodução. Destacam-se nas estratégias do capital: i- a violência institucional, ou a dominação mantida pela coerção mais extrema; ii- o genocídio da população pobre e negra; iii- o investimento ideológico nas propostas reacionárias sobre relações sociais estruturantes como questões de gênero, raça, credos; iv- a exaltação da ideologia e da prática de empreendedorismo, empregabilidade, inserção e responsabilidade social, realizada por grandes grupos capitalistas através de fundações, ONGs e entidades empresariais, como forma de mascarar a exploração e o desemprego estrutural; e v- a desestruturação dos serviços públicos com vistas à sua privatização, o que acaba reverberando em precarização das relações de trabalho no interior do funcionalismo público.

Outro matiz presente são as mudanças objetivas na conformação da classe - com novas formas de absorção da força de trabalho - e, consequentemente, o advento de um novo perfil. Tais mudanças geram diferentes formas de reação, pauta, métodos, sujeitos de luta e temporalidade, que são adensadas pelo distanciamento dos espaços organizativos clássicos - sindicatos e partidos - da classe trabalhadora. Elementos esses de burocratização e desconhecimento de quem é de fato a classe trabalhadora hoje - da qual são expressão as recentes mobilizações dos trabalhadores de aplicativo no Brasil. Tais alterações trabalhistas são de duas naturezas: uma interna, que envolve modificações na composição, no gênero, na especialização exigida dos trabalhadores em seus afazeres profissionais e nas ocupações dos postos de trabalho; e outra externa, que envolve a relação com o capital e, em sua atual fase de acumulação, promove uma brutal diminuição do uso do trabalho vivo. Um mundo do trabalho da era do "[...] privilégio da servidão [...]”, como afirma Antunes (2018, p. 14).

Nesse processo de resistência identifica-se que: i- alguns movimentos sociais demonstram novas formas de confronto com os interesses dominantes e expressam diferenças com relação à trajetória organizativa e à cultura política de esquerda no Brasil; ii- tais movimentos se relacionam com novas formas de representação coletiva da classe trabalhadora, tendo em vista sua metamorfose na atualidade; e iii- essas lutas e resistências se dão em um quadro de ainda forte refluxo e em um contexto de fragmentação e ausência de unidade forjada pela prática coletiva de luta.

É diante desse panorama que - na luta pela sobrevivência no cenário carioca destacam-se alguns movimentos auto-organizados das favelas cariocas como a Frente CDD (Frente de Articulação da Cidade de Deus); o Nós por Nós pela favela; o Movimenta Caxias os Coletivos de mulheres negras; a articulação dos Agentes Comunitários de Saúde de Manguinhos no enfrentamento às violências das forças 
policiais que dificultam a atuação da saúde; o movimento juntos pelo Complexo; a Redes da Maré; o Brota na Lage do Borel; além de múltiplos coletivos que são desconhecidos mas agrupam, organizam e se articulam entre si para responder de forma mais rápida às demandas da população não atendida pelo Estado. Ainda contamos, nas periferias cariocas, com movimentos sociais mais tradicionais, como o Movimento dos Trabalhadores Sem Teto (MTST) e o Movimento de Luta nos Bairros (MLB), além de organizações não governamentais tradicionais nas favelas. Há diversos pontos de unidade entre esses distintos movimentos e os processos auto-organizativos que trazem renovação de método, na luta e na organização. Sob tal sentido, dois aspectos devem ser destacados, necessariamente, como pontos de contato. Por um lado, a independência dos movimentos frente ao Estado e aos patrões; por outro, o respeito à particularidade de cada indivíduo-sujeito coletivo no contexto da conformação da classe trabalhadora na atualidade.

É a partir desse ponto que o caráter histórico necessita ser resgatado em sua essência. As distintas experiências de auto-organização em curso nas periferias e favelas do país se alimentam objetivamente dos processos de luta travados, sejam os mais estruturantes nos espaços organizativos da classe, sejam as jornadas de 2013 que questionaram as formas organizativas e de luta. Na certeza de que a única solidariedade possível para os trabalhadores é a desenvolvida pelos próprios trabalhadores, grupos se organizam para distribuir alimentos, material de limpeza, e informações para ajudar no cadastramento dos trabalhadores nos programas emergenciais do governo. Constroem rede para cuidado de crianças e idosos nas periferias, distribuem roupas e outros utensílios para a reprodução material, como água potável. Esses grupos auto-organizados ou incentivados por organizações não governamentais, igrejas e grupos políticos, evidenciam o distanciamento das organizações clássicas da classe trabalhadora dos territórios periféricos.

Ainda como reação da classe trabalhadora à exploração capitalista e sua opção pela defesa dos lucros, em cidades brasileiras explodiram manifestações antifascistas, impulsionadas pelas torcidas organizadas de futebol. A essas, a partir do brutal assassinato de Jorge Floyd nos Estados Unidos, foi incorporado o grito antirracista eu não posso respirar, agregando a pauta racial às manifestações de rua. Ainda há, como expressão da reação de segmentos da classe trabalhadora, a greve dos trabalhadores de aplicativo de entrega domiciliar e a greve de transporte em algumas cidades que, de forma aligeirada, impuseram a reabertura da cidade como se vivêssemos em tempos ditos normais. Vemos assim, novas reivindicações, ações e formas de se organizar que carregam em si as experiências construídas historicamente pela classe trabalhadora.

Algumas considerações podem nos ajudar nessa compreensão. Primeiramente, a transformação das necessidades em bandeiras exige que se desnaturalize a Questão Social, pautando novamente o antagonismo dos interesses de classe, como afirma Iamamoto e Carvalho (1995). As necessidades objetivas movem os indivíduos quando estes têm consciência das condições reais, o que transforma necessidades objetivas em sociais e desencadeia um novo processo nas relações sociais que estão postas. Em segundo lugar, a base social dessas formas organizativas pode, no geral, ser classificada como popular, no sentido de que é composta por setores sociais que empobreceram 
com o modelo de desenvolvimento e foram excluídos do processo político, econômico e social. Há, contudo, particularidades quanto ao modo como se movem, apresentando diferenciações a partir das relações que estabelecem com o grupo a que se vinculam e com o seu território.

\section{Considerações finais}

Ao escrever as linhas finais deste artigo, o Brasil contabilizava mais de 1.350.00o infectados e 57.000 mortes. São vidas ceifadas por uma pandemia que não escolhe pessoas, região, cor ou classe social, mas que explicitou a suscetibilidade à doença dos moradores das favelas. A Covid-19 evidenciou não só a crise econômica, política e social em que o país se encontra, mas também os problemas que atingem os favelados para além da violência cotidiana mostrada pela mídia, explicitando a desigualdade social do país e a insegurança crônica promovida e naturalizada pelo Estado.

Se em um primeiro momento, a desigualdade fica explícita, em um segundo a pandemia explicitou formas de resistência, solidariedade e organização construídas pelo segmento mais pauperizado da classe: a articulação das redes de solidariedade externa e interna das favelas, os coletivos da mídia local, os movimentos sociais, as organizações não governamentais comprometidas com esse público e a mobilização das redes locais. Ou seja, observou-se o processo histórico dos pobres ajudando os pobres, já que os auxílios dos governos chegaram de forma insuficiente e tardia.

De fato, o determinante deste processo - que pode ser a amálgama que incrementaria seu potencial e possibilitaria uma unidade estratégica, reconhecendo a classe formada por iguais na diferença -, é a referência ao projeto estratégico de ruptura com a ordem estabelecida, superando as amarras reformistas e imediatistas no enfrentamento com o capital. A partir de um processo real de mistura dos que estão em espaços distintos, mas pertencem ao mesmo lugar de classe, se faz necessário absorver e trocar experiências entre os diferentes da classe trabalhadora, aprender e ensinar a partir do processo de organização e politização com a experiência de enfrentamento, organização de base, desvendamento da realidade, forjando assim a única unidade real - que se dá pela práxis cotidiana e nos tira do lugar consolidado. Neste momento as cunhas de avanço são as ações de solidariedade que materializam a relação entre os trabalhadores, evidenciando a desigualdade básica: a desigualdade de classe. Aos sujeitos políticos nessa nova configuração social fica o desafio de reconstruir os marcos das relações sociais, reafirmando a solidariedade de classe como princípio norteador do novo porvir.

\section{Referências}

ANDRADE, Carlos Drummond de. "Crônica das Favelas Nacionais". Jornal do Brasil, Rio de Janeiro, 6 out. 1979.

ANTUNES, Ricardo. O privilégio da Servidão. São Paulo: Editora Boitempo, 2018.

ANTUNES, R. Os sentidos do trabalho. São Paulo: Boitempo, 1999. 
ARROYO, Miguel G. "As indagações desestabilizadoras do injusto viver" In: VALLA, Victor Vicent; ALGEBAILE, Eveline; GUIMARÃES, Maria Beatriz. Classes populares no Brasil: exercício de compreensão. Rio de Janeiro: Escola Nacional de Saúde Pública Sergio Arouca- ENSP, 2001.

BEHRING, E.; BOSCHETTI, I. Política Social: fundamentos e história. São Paulo: Cortez, 2006. (Biblioteca Básica do Qu, v. 2).

CHESNAIS, F. A mundialização do capital. São Paulo: Xamã, 1996.

FARAGE, Eblin. Estado, território e cotidiano no Complexo de Favelas da Maré. Tese (Doutorado em Serviço Social) - Programa de Pós-Graduação em Serviço Social, Universidade Estadual do Rio de Janeiro, Rio de Janeiro, 2012.

FERNANDES, Fernando Lannes. O gerenciamento dos párias urbanos no Rio de Janeiro: uma reflexão sobre a produção dos mecanismos de controle e contenção sócioespacial e dos espaços de constrangimento. Convergência, México, 2011.

FERNANDES, F. Capitalismo dependente e classes sociais na América Latina. Rio de Janeiro: Zahar, 1991.

GRAMSCI, Antonio. Cadernos do Cárcere volume o3 (Maquiavel - notas sobre o Estado e a Política). Rio de Janeiro: Editora Civilização Brasileira, 2000.

HARVEY, David. A produção capitalista do espaço. São Paulo: Editora Annablume, 2006.

IAMAMOTO, Marilda V.; CARVALHO, R. Relações sociais e Serviço Social no Brasil: esboço de uma interpretação histórico-metodológica. 4. ed. São Paulo: Cortez; CELATS, 1995.

IASI, Mauro Luiz. As metamorfoses da consciência de classe: o PT entre a negação e o consentimento. São Paulo: Editora Expressão Popular, 2006.

LEFEBVRE, Henry. A vida cotidiana no mundo moderno. São Paulo: Editora Ática, 1991.

MANDEL, E. A crise do capital. Campinas: Ed. UNICAMP; Ensaio, 1990.

MARX, Karl. O capital: crítica da economia política. Livro I. Rio de Janeiro: Civilização Brasileira, [1867] 2003.

NETTO. José Paulo. “Cinco notas a propósito da 'Questão Social”'. Temporalis, Brasília: ABEPSS, ano 2, n. 3, pp. 41-49, jan./jun. 2001.

SILVA, J. de S. et al. (Org.). O que é Favela, Afinal? Rio de Janeiro: Observatório de Favelas, 2009. 
SILVA, Jailson. "Um espaço em busca de seu lugar: as favelas para além dos estereótipos”. In: TERRITÓRIO: territórios. Niterói: Editora EDUFF, 2007.

SILVA, Eliana Sousa. O contexto das práticas policiais nas favelas da Maré: a busca de novos caminhos a partir de seus protagonistas. 2009. Tese (Doutorado em Serviço Social)-Programa de Pós-Graduação em Serviço Social da PUC-RJ, Rio de Janeiro, 2009.

VALLADARES, Licia do Prado. A invenção da favela: do mito de origem à favela.com. Rio de Janeiro: FGV, 2005.

WILSON Witzel: 'A polícia vai mirar na cabecinha e... fogo'. Veja, Redação, São Paulo, 1ํㅡ. nov. 2018.. Disponível em: https://veja.abril.com.br/politica/wilson-witzel-a-policiavai-mirar-na-cabecinha-e-fogo/. Acesso em: 29 jun. 2020.

Francine HELFREICH Contribuiu na concepção, delineamento e redação do artigo. Contribuiu também na revisão crítica, assim como na aprovação da versão a ser publicada.

Assistente Social, mestre e doutora em Serviço Social nos respectivos programas de pósgraduação da UFRJ e UERJ. Professora da Escola de Serviço Social da UFF, do Programa de Pós-Graduação em Serviço Social e Desenvolvimento Regional da UFF e coordenadora do Núcleo de Estudos e Pesquisas sobre Favelas e Espaços Populares (NEPFE).

Eblin FARAGE Contribuiu na concepção, delineamento e redação do artigo. Contribuiu também na revisão crítica, assim como na aprovação da versão a ser publicada.

Assistente Social, mestre e doutora em Serviço Social nos respectivos programas de Pós Graduação em Serviço Social da UFRJ e UERJ. Professora da Escola de Serviço Social da UFF, do Programa de Pós-Graduação em Serviço Social e Desenvolvimento Regional da UFF e coordenadora do Núcleo de Estudos e Pesquisas sobre Favelas e Espaços Populares (NEPFE).

Marina Barbosa PINTO Contribuiu na concepção, delineamento e redação do artigo. Contribuiu também na revisão crítica, assim como na aprovação da versão a ser publicada.

Assistente Social, mestre em Serviço Social e Doutora em História PPG-UFF. Professora associada da Faculdade de Serviço Social da Universidade Federal de Juiz de Fora (UFJF) Pesquisadora do Núcleo Geografia, Espaço e Ação (Nugea-ICH-UFJF) 